Aktobe University. S. Baisheva, Kazakhstan

Urazgaliyevama@mail.ru

ШЫНЫБЕК БУХАРБАЕВ

Aktobe University. S. Baisheva, Kazakhstan

sh.bukharbayev@ausb.kz

ГАЛЫМ МусИРОВ

Aktobe University. S. Baisheva, Kazakhstan

mysirov@mail.ru

\title{
REFORMING THE TAXATION OF PERSONAL INCOME AND THE NEED FOR UNIVERSAL DECLARATION IN KAZAKHSTAN
}

\section{Реформирование налогообложения доходов физических лиц инеобходимость всеобщего декларирования в РК}

\begin{abstract}
The article examines trends and problems of taxation of individuals in the current system, the need to introduce universal declarations in Kazakhstan. The choice of this topic is caused by fact that state, business sector and population of Kazakhstan should not remain indifferent to this tax, as it is one of the stable sources in budget revenue part. The scientific generalization presented in this article is a continuation of scientific disputes rethinking, interpretations, approaches of scientists - economists of developed and developing countries to issue of taxation of the population.

The search for the right, effective ways to solve the problems above can be realized through the interaction of scientific people and leading practitioners - economists with participation and discussion of this issue in various scientific forums at regional and national levels, approbation of speeches at scientific and practical conferences, publication of articles in scientific publications of countries near and far abroad and in Kazakhstan with the purpose of attracting attention of interested taxpayer categories.
\end{abstract}

Keywords: tax, budget, Declaration, reform, taxation 


\section{Аннотация}

В статье исследованы тенденциии проблемы действующей системы налогообложения физических лиц, необходимость введения всеобщего декларирования в Казахстане. Выбор темы вызван тем, что данный налог не должен оставлять равнодушным государство, деловой сектори население Казахстана, так какявляется одни миз стабильныхисточников доходной части бюджета. Научное обобщение, представленное в данной статье является продолжениемпереосмысления научных споров, трактовок, подходов ученых - экономистов развитых и развивающихся стран к вопросу налогообложения населения.

Поиск правильных, эффективных путей решения обозначенных проблем может быть реализован через взаимодействие людей науки и ведущих практиков - экономистов с участием и обсуждением этого вопроса в различных научных форумах регионального и республиканского уровней, с апробацией выступлений на научно - практических конференциях, публикацией статей в научных изданиях стран ближнего и дальнего зарубежья и в Казахстане с целью привлечения внимания заинтересованных категорий налогоплательщиков.

Цель исследования: показатьособенностии результаты поэтапного реформирования индивидуального подоходного налогообложения (налога на доходы физических лиц) в Казахстане с последующим исследованиемего дальнейшего развития, изучить обоснования зарубежных и отечественных ученых - экономистов различных подходов к вопросам эффективности использования прогрессивной или плоской шкалы налогообложения доходов физических лиц в жизни общества на конкретном этапе развития экономики. Кроме того, раскрыть сложности введения всеобщего декларирования в Казахстане.

Методы: в ходе исследования использованы общенаучные методы: индуктивный и дедуктивный, эмпирический и экономико-статистический методы, чтобы выявить современное состояниеиндивидуального подоходного налогообложения (далее ИПН) в Казахстане и предположитьходреализации всеобщего декларирования на начальной стадии своего развития в условиях происходящихрыночных реалии страны, обозначить существующие проблемы для принятия оперативных и стратегических мер. 
Вывод: ИПН является одним из источников доходной части местного бюджета, его доля в налоговых поступлениях в бюджет в Казахстане на сегодняшний день занимает в среднем 6-13,5\%, и считается пусть не неосновным, но стабильным доходным источником, поэтому требует дальнейшего теоретико - практического исследования.

КЛЮЧЕВЫЕ СЛОВА; бюджет, налогобложение, индивидуальный подоходный налог, всеобщее декларирование, ребормирование.

\section{Введение}

В последнее время налог на доходыфизических лиц(далее НДФЛ) в Казахстане характеризуется низким уровнем собираемости данного налога по сравнению с развитыми странами. Также отмечается актуальность и недостаточная изученность влитературных источниках вопросов статистического исследования поступлений индивидуального подоходного налогообложения в бюджет.

Характер проблем налогообложения физических лиц отличается многогранностью, сложностьюиспользования современных статистических методов структурного и динамического анализа состояния исследуемого экономического процесса.

Научные результаты, выявленные с применением новых оптимальных подходов к исследованию, позволят внести определенный вклад по совершенствованию налоговой политики государства и обосновать меры по достижению эффективности проведения налоговых реформ с использованием преемственности передового опыта развитых стран.

\section{Современное состояние и проблемы индивидуального подоходного налогообложения (НДФЛ)}

Проблемы индивидуального налогообложения касаются интересов всего активного населения, при этом являясь одним из важных источников доходной части бюджета. Если обратиться к статистике, то за последние годы сложилась такая тенденция, когда индивидуальный подоходный налог (ИПН) наряду с корпоративным подоходным налогом 
и налогом на добавленную стоимость занимает одно из лидирующих мест в бюджете страныи при динамическом анализе его современного состояния выявлено следующее: (таблица1).

\section{Таблица 1}

Структурный анализ поступления налогов в государственный бюджет за период 2011-2017 гг

\begin{tabular}{|c|c|c|c|c|c|c|c|}
\hline \multirow{2}{*}{$\begin{array}{c}\text { Наименование } \\
\text { налога }\end{array}$} & \multicolumn{6}{|c|}{ Годы } & \multirow[b]{2}{*}{2017 r } \\
\hline & 2011 r & 2012 r & 2013 r & 2014 r & 2015 r & 2016 r & \\
\hline КПН & 26 & 25 & 22 & 23,5 & 21 & 19,8 & 25,7 \\
\hline ИПН & 9 & 11 & 10 & 12 & 9,5 & 9 & 13,5 \\
\hline $\begin{array}{c}\text { Социальный } \\
\text { налог }\end{array}$ & 10 & 9 & 9 & 9,2 & 8,5 & 9 & 10,4 \\
\hline НДС & 28 & 25 & 24,5 & 22 & 20,5 & 25 & 30,7 \\
\hline Прочие налоги & 25 & 29 & 35 & 33,3 & 40,5 & 37,2 & 20 \\
\hline Итого & 100 & 100 & 100 & 100 & 100 & 100 & 100 \\
\hline
\end{tabular}

П р и м е ч а н и е - составлено по источнику [1]

По данным таблицы 1 видно, что по налоговым поступлениям по данному источнику выявлена неравномерная динамика: в 2010 году доля ИПН в общем объеме налоговых поступлений составила - 6\%, за период 2011-2014 годы выявлен рост с 9\% до 12\%, а с 2015 года наблюдается снижение уд. веса ИПН до 9\%, а в 2017 году наблюдается резкое повышение доли, которое составило $-13,5 \%$. В целом, надо констатировать, что в структуре налоговых поступлений доля ИПН в государственном бюджете за рассматриваемый период незначительна и колеблется в пределах $9-13,5 \%$.

В общем объеме государственного бюджета с учетом Национального фонда в тренде корпоративный подоходный налоги налог на добавленную стоимость, доля которых составляет около 25\%, а удельный вес ИПН всего лишь в среднем 9\% - 12\%. Сравнительный анализ позволил выявить, что в развитых странах бюджеты формируются в основном 
за счет налогов с физических лиц. В частности, доля ИПН в консолидированном бюджете составляют в США - 60\%, в Великобритании, Швейцарии, Швеции - 40\%, странах ОЭСР, в среднем, - 30\%, а вместе с взносами на социальное страхование, взимаемыми с общей базы, как и подоходный налог, - 55\% (Alston, Kearl, Vaughan, 1992).

С позиций налогоплательщика налог на доходы физических лиц является одной из причин ухудшающего его благосостояния, так как это вызывает уменьшение его дохода и при этом возможность потребления рыночных благ снижается. При уплате НДФЗ обратной связи не происходит и не компенсируются при этом общественные блага, поэтому у налогоплательщика складывается впечатление, что индивидуальный подоходный налог перечисляется в пользу государства, ухудшая благосостояние населения.

При налогообложении физических лиц большое значение имеет понятие «доход», но на сегодняшний день нет однозначного исчерпывающего понятия, а законодательство европейских государств его трактует по-разному (Умирбекова, 2005) (Оценка влияния создания, 2010).

В налоговом законодательстве различных государствв наиболее общем виде доход включает заработную плату рабочих и служащих, другие формы вознаграждения за труд, в том числе в натуральной форме, доходы от некорпорированного бизнеса (в том числе - партнерства, фермерства), от капитала (проценты, дивиденды), пенсии, пособия, алименты, платежи по авторским правам и лицензиям (Сайт, Министерства) (Сайт, Армянское)( Бобоев, Мамбеталиев, Тютюрюков, 2002).

Кроме того, в данное понятие «валовой личный доход», включают поступления, которые с позиции налогового права считаются доходами (арендная плата за жилье, чаевые официантов, таксистов, парикмахеров и другие) [(Информационное сообщение) ( Minarik, 2009)].

Данный налог на восприятие налогоплательщиков Казахстана является негативным, воспринимается как безысходное отчисление денег или действие, которое невозможно избежать на уровне закона. При всем при этом налогоплательщик не имеет четкого представления 
о том, что он получает взамен и получает ли что-либо вообще (в каком объеме и размере), куда уходят деньги и как они работают.

На самом деле налогоплательщик получает услуги государства в сферах жизненно-важных интересов человека, а именно здравоохранение, образование, организация охраны порядка, охрана окружающей среды и других услуг, только качество предоставляемых государством услуг требует должного уровня развития. Кроме вышеперечисленных услуг, государство в интересах общества, нации или государства за счет средств бюджета проводит различные мероприятия международного значения, в частности, ЭКСПО, САММИТЫ, спортивные олимпиады, музыкальные форумы с целью представления нашей страны во всех аспектах экономической, социальной, культурной, спортивной жизни.

Для цивилизованного общества очень важно реализация качественного перераспределения денежных средств руками государства, при этом добиваясь экономической эффективности и социальной справедливости.И это касается и регионального уровня, поскольку региональное перераспределение является также одним из основных проблем общества.

Научный мир спорит о том, какая шкала налогообложения наиболее эффективна в решении вопросов снижения неравенства в доходах: плоская или прогрессивная. Так, например, в Y. Gorodnichenko, J. MartinezVazquez, K. Sabirianova Peter в 2009 году, сделали вывод о том, что введение плоской шкалы не привели к существенному росту поступлений по данному налогу. Но, когда в экономике государства имеет постоянное уклонение от уплаты налогов, то такая реформа подоходного налога приведет к росту уровня собираемости налогов посредством реализации правосознания и законопослушания (Gorodnichenko, Vazquez, Sabirianova, 2009).

Эмпирические исследованияпозволили авторам придти к выводам, что применение плоской шкалы налога в развивающихся странах даст больше возможности уменьшить развитие теневой экономики и улучшить процесс распределения доходов путем прямого перераспределения. Это как раз есть компромисс между эффективностью и справедливостью. По мнению D. Duncan и K. Sabirianovaэто объясняет, почему 
плоские налоги являются относительно более популярными в развивающихся странах, чем в развитых странах. (Shigehiro, Schimmack, Diener, 2012).

Д. К. Джонстон (2005) также выступает за прогрессивную шкалу налогообложения: чем богаче человек и чем выше его доход, соответственно этому и должен выплачивать налоги (Хасси, Любик, 1992) (Ricketts, Shoesmith, 1992) (Johnston, 2005).

В западных странах, в частности в Польше, проводят эмпирические наблюдения и сравнительный анализ эффективности функционирования прогрессивного налога и гипотетического эффекта налогообложения по плоской шкале индивидуального подоходного налога (Krajewski, Pił, 2017).

В большинстве развитых и развивающихся странах распределение доходов становятся все более искаженными в последние десятилетия (Stiglitz 2012; Piketty2014).Использование эмпирических данных из стран ЕСдают подтверждающие доказательства того, что более высокая налоговая ставка оправдана, когда она вводится на небольшую группу людей (менее 20\%), а в других случаях это может привести к оттоку из страны более квалифицированных профессионалов с высокой заработной платой. Такая картина со снижающейся эластичностью предложения рабочей силы наблюдается в Норвегии, США, Великобритании и Австралии, (Jin, FitzRoy, Econ, 2017).

Также рассматриваются модели и создание инструмента, чтобы помочь политикам определить налоговые шкалы и ставки, которые имели бы оптимальный перераспределительный эффект с учетом обеспечения бюджетных потребностей и недопущения негативных последствии на благосостояния домохозяйств. Такая работа подпадает под контекст проведения налоговой рефоры, которая не касается вновь построенной оптимальной модели налогообложения,, а скорее, направленная на оптимальную реформу существующего подоходного налогообложения, например такой подход применительно к Бельгии. (Roosevelt, 1983).

Однако, налоговая система льготы и налоговые надбавки и другие характеристики налоговой системы являются предметом дискуссии и полемику ведут не только среди экономистов, но и среди других спе- 
циалистов и общественности. Это является причиной того, что индивидуальные налоговые системы значительно неоднородны и обычно включают в себя различные национальные спецификации. Одновременно, многие развитые страны интегрировали в OECD3 и в настоящее время настал значительный бюджетный кризис, в рамках которого они испытывают проблемы с погашением своих краткосрочных и долгосрочные обязательств. В связи с этим сами правительства подвергаются надзору со стороны финансовых рынков и поэтому они вынуждены консолидировать государственный бюджет. Кризис государственных финансов обычно решается двумя конкретными каналами - канал сокращения государственных расходов, и канал повышения налогов, или налог рента. (Macek, 2014).

Вопрос о том, какая же ставка индивидуального подоходного налога более эффективна и справедлива: плоская или прогрессивная шкала активно по сей день продолжают обсуждать экономисты, политики, социологи и, кроме того, этим вопросом интересуются не только в развивающихся странах, но и в развитых странах, таких как Канада, США. Не стоит забывать о том, что плоская шкала налога всегда в первую очередь выгодна богатым, нежели бедным. Конечно, даже в денежном эквиваленте даже $10 \%$ от дохода богатых - это могут быть суммы, выраженные в десятках тысяч долларов. Но в тоже время мы прекрасно понимаем, что выплачивать 10\% куда проще и "не так обидно», чем скажем там 20\%, 30\% или даже 40\% (Аббасова).

В своем Послании народу Казахстана (2009) годобращено большое внимание на вложения в человека, при этом налог на доходы физических лиц, как активный доходный инструмент очень востребован, так как способствует увеличению доходной части бюджета, а из бюджета определенная часть необходима для воспроизводства человеческого фактора, а также решаются вопрос финансирования и других социальных сторон в области повышения уровня и качества жизни общества в соответствии приоритетными направлениями государства (Назарбаев, 2009).

Обобшая вышеутвержденные положения, надо отметить, что решение проблем НДФЛ всегда будет актуальным и находиться в центре бурного обсуждения учеными, практиками и т.д. 


\section{Всеобщее декларирование в Казахстане как один из путей совершенствования налогообложения физических лиц}

Для анализа современных проблем в сфере налогообложения доходов физических лицнеобходимо:

1) дать оценку отношений населения по переходу:

- к всеобщему декларированию индивидуальных доходов;

- к прогрессивной шкале налогообложения.

2) прокомментировать природууклонения от уплаты налогови объяснить отсутствие налоговых льгот по ИПН.

По вопросу перехода к всеобщему декларированию доходов населения получены неоднозначные мнения, но реализация данного новшества неминуема. При проведении данной реформыможно получитьследующие результаты:

- выявление теневой экономики в «свет»;

- расширение налогооблагаемой базы, значит, снижение налоговой нагрузки на отдельно взятого плательщика;

- повышение уровня налоговой культуры в обществе;

- предоставление потенциала возможностей пользоваться системой вычетов и льгот.

В целом все это дает возможность населению достойно выполнить свою конституционную обязанность,Кроме того, функционирование системы всеобщего декларирования индивидуальных доходов потребует наличия документов, для подтверждения расходов при заполнении деклараций, поэтому налогоплательщики будут требовать документального оформления организациями, предоставляющие медицинские, образовательные, страховые и другие услуги.

Все эти действия со стороны населения заставят экономические агенты (больницы, школы, платные курсы, спортивно - оздоровительные мероприятия и другие субъекты) показывать свои доходы через кассовые аппараты, тем самым способствуя увеличению налогооблагаемой базы по КПН. 
Чтобы разобраться в проблемах налогообложения физических лиц были изучены материалы эпизодических бесед со специалистами экономического профиля, работодателями и с отдельными людьми в повседневной жизни, ознакомились с комментариями аналитиков и экспертов.

В результате, отдельные экспертыратуют за упраздненную в Казахстане систему прогрессивной шкалы налогообложения, которая не выполняла функцию перераспределения налогового бремени и что такая реформа не дала ожидаемых результатов. А бухгалтера, которые занимаются начислением заработной платы и взиманием ИПН оказались сторонниками плоской шкалы и констатировали, что налоги выплачиваются по понятной, фиксированной, приемлемой ставке $10 \%$ и данная система очень комфортна.

Поэтому, надо пройти определенный путь, выждать время и провести сравнительный анализ двух систем, так как обе системы апробированы в Казахстане.

По вопросу сокрытия доходов многие выбирают неофициальную заработную плату в связи с недоверием к пенсионной системе и в целом к экономической системе государства, так как имели место факты обмана, в частности (государственное медицинское страхование в 90 - е годы) и заблуждений.

Серьезность проблем в области индивидуального налогообложения в сфере недостаточного использования вычетов с доходов в практической жизни хозяйствующих субъектов тоже вызывает реакцию и дискуссию среди населения Казахстана, хотя для других стран реализация системы вычетов и льгот является привычным.

По мнению депутата Мажилиса Парламента РК, председатель Комитета по финансам и бюджету, профессора Г. Карагусовой, которая подтверждает функционирование в Казахстане высоких ставок налогов и наличие слабой системы вычетов для физических лиц: и она выступила со словами: «Необходимо сначала обеспечить систему вычетов для физического лица, чтобы создать условия для его гармоничного развития как образованного, здорового и законопослушного гражданина государства» (Материалы Пятого, 2010). 
Подобной точки зрения придерживаются и западные исследователи. Так, JamesA. Yunker (2010) в своей статье «Capitalwealthtaxationasapoten tialremedyforexcessivecapitalwealthinequality» приходит к выводу, что общественные услуги, такие как образование и здравоохранение, распределяются более равным способом, чем доход, таким образом, включение их в более широкую концепцию экономических ресурсов снижает неравенство, хоть и с малыми изменениями в рейтинге стран. При этом учет потребительских налогов расширяет неравенство, хотя и не настолько, насколько его сужает учет общественных услуг (Yunker, 2010).

Например, во Франции из общего дохода вычитаются нижеследующие суммы расходов при условии, что они были осуществлены в профессиональных целях и оплачены из собственных средств:

- транспортные расходы;

- расходы на питание;

- расходы на образование;

- расходы на приобретение вычислительной техники;

- расходы, относящиеся к личным помещениям, используемым в профессиональной деятельности;

- расходы на спецодежду и т.д.

Существуют определенные вычеты, связанные с семейными обязанностями:

- расходы по охране дома;

- расходы на содержание маленьких детей в яслях, детских садах и т.д.;

- расходы по обучению ребенка;

- расходы на страхование жизни и т.д.

Однако необходимо учитывать, что при достаточно большом объеме налоговых вычетов во Франции применяется высокая ставка индивидуального подоходного налога. (Курляндская, 2010).

В результате анкетирования выяснено, что имеющиеся льготы в налогообложении физических лиц практически не используются: 60,8\% респондентов отметили, что у них нет налоговых льгот, $34,3 \%$ не знают и только $4,9 \%$ сообщили о том, что имеют льготы. 
Основными причинами, по которым население не пользуется налоговыми льготами, явились:

1) не знание налогового законодательства - 69,6\% из опрошенных,

2) отказ со стороны работодателя (что фактически является нарушением налогового законодательства) - 5,9\%,

3) льготы в ощутимой степени не повлияют на мой доход - 22,5\% респондентов.

Кроме того, по мнению аналитиков, существуют пробелы в законодательстве, где четко не прописан механизм принятия расходов на вычеты. На практике для бухгалтерии непонятки и сложности законодательства по поводу налоговых льгот создают проблемы при налоговой проверке и что для них это совершенно не нужная работа (Казаков, 2007).

Напомним, что президент Казахстана Нурсултан Назарбаев подписал закон, касающийся всеобего декларирования населения и предполагается два этапа: с 2017 года заполнять документ обязаны госслужащие, работники квазигосударственного сектора и бюджетных организаций, с 2020 года - все остальное население.

Но для начала реформы декларирование не должно нести репрессивный смысл - заставить людей платить налоги. Наоборот, его надо внедрять как экономический стимул, чтобы населениеиспользовало потенциал возможности поставить на вычет свои расходы. Также надо отметить, что везде, где есть декларирование, внедрена прогрессивная шкала ИПН (Барышева, 2015).

В жизни общества накопилось много нерешенных проблем, связанных с внедрением всеобщего декларирования физических лиц. Так, в Казахстане нет ясности в вопросе реформирования специальных налоговых режимов, так как в нашей стране 90\% самозанятого населения работают в данном режиме.

По статистике в Казахстане доля «теневой» экономики в ВВП составляет 20\% и налогообложение «заграничных» доходов казахстанских резидентов - большая проблема. Если напомнить, что какой-то житель нашей страны имеет акции Microsoft, и они котируются за ру- 
бежом или информация о предметах роскоши, непонятно, как это все будет отражаться в декларациях? (Трудности запуска в Казахстане).

Введение всеобщего декларирования в любой стране сопровождается общественной дискуссией о плюсах и минусах этой системы. Противодействующими аргументами за введение деклараций являются:

- во - первых, прямые затратыгосударства на внедрение и поддержание такой системы, которые могут не окупиться в первое время.Простые затраты это заполнение анкет и их архивация, а более серьезные затраты нужны на внедрение качественной системы проверки данных, указанных в декларациях.

- во-вторых, косвенные потери, которые несет государство вследствие потери кадров. Это увольнение публичных должностных лиц (ПДЛ) в связи с введением обязанности декларировать доходы и имущество наблюдалось в ряде стран, например в США в 1960-е годы и в Румынии в 2005 г. В Германии до сих пор продолжаются дебаты относительно системы деклараций имущества депутатов.

В качестве ключевого аргумента против деклараций приводится тот факт, что это недопустимо для представителей малого бизнеса или индивидуальных предпринимателей, так как это приведет к разглашению их коммерческих секретов. В итоге эти люди не будут участвовать в выборах, и это приведет к ухудшению качества представительной демократии (Всеобщее декларирование в Казахстане).

В большинстве современных стран доводы в пользу введения деклараций перевесили доводы против. Из 149 стран - клиентов Всемирного банка, согласно данным за последние годы, лишь 43 страны не требовали декларирования. Почтиполо винаизэтих 43 страннаходятсяв Африке, изевропейски хстран требованиепредо ставлятьдекларацию ПД Лотсутствуеттольков Эстонии. (Лукьянова, 2010).

Процесс декларирования начат, но представители судебных органов обращают внимание на риск того, что в декларации может быть указана недостоверная или неполная информация и предлагают суровую меру - уголовную ответственность. И таков международный опыт. 
В данное время, декларации заполняют все государственные служащие, их супруги, а также лица, уволенные с государственной службы по отрицательным мотивам. В случае, если декларация не предоставляется или предоставляются неполные или недостоверные сведения, установлен штраф - 50 МРП, поэтому надо тщательно отработать и выстроить систему всеобщего декларирования населения (Наненко, 2012).

Реформирование налоговой системы Казахстана в условиях глобализации должна проводиться с учетом преемственности международного опыта и с использованием достигнутого результатов собственного накопленного опыта. Стратегия вхождения Казахстана в числе тридцати наиболее конкурентоспособных стран мира, в целях дальнейшей модернизации и диверсификации экономики страны, является одним из приоритетных задач, которая направлена на совершенствование фискальной дисциплины и повышения уровня эффективности современной налоговойполитики.

\section{Выводы}

НДФЗв Казахстане входит в число стабильных источников доходной части бюджета. Практика показывает, что данный налог не соответствует уровню развития аналогичных налогов в развитых странах. Поэтому, назрела необходимость пересмотра применяемой в Казахстане формы взимания ИПН, поиска баланса составляющих элементов налога, обеспечивающего высокий уровень налоговых поступлений в бюджет и справедливое перераспределение доходов населения в соответствии с приоритетными направлениями социально-экономическогоразвития.

Результаты исследования определили следующее:

- Изучение процесса развитияНДФЛ в Казахстане дало возможность оценить потенциал его применения на практике и определить его значение для современной экономикистраны;

- Анализ реформиндивидуального подоходного налогообложения позволил нам понять природную сутьданного налога, систематизировать этапыего развития и формироватьпрочную основудля дальнейшего развитиястраны;

- В процессе исследования выявлено, что социальная направлен- 
ностьданного налогав зарубежнойпрактике реализуетсяв налоговых льготах т.е использованиеналоговых льгот при расчете ИПНсчитается эквивалентом государственным расходам Правительства для достиженияцелей социального характера.

В данное время назрели предпосылки для реформирования индивидуального подоходного налогообложения для решения ряда задач социально-экономической направленности.

Выбор эффективности или справедливости плоской или прогрессивной шкалы налогообложения на сегодняшний день, обсуждаемый и поднимается не только в Казахстане, но и в США и Канаде, так как плоская шкала выгодна более богатым слоям населения, в то же время каждый налогоплательщик понимает, что выплатить 10\% намного комфортнее, чем 30 - 40\%, которые вынуждают прибегать к уклонению от уплаты налогов.

Таким образом, в Казахстане должна функционировать система НДФЗ, способствующая обеспечению баланса интересов государства экономическогои социального характера, чтобы дать возможность ИПН решать задачу оптимального перераспределения доходов. На данном этапе развития государства надо признать совершенно справедливой функционирование единой тарифной ставки (плоскойшкалы) НДФЛ и она призвана удовлетворять интересы и государства и налогоплательщиков.

Если не происходит процесс перераспределениядоходов, то это способствует наступлению социально-экономическогорасслоения общества, которое обязательно приводит к социальной напряженности в стране.

Следовательно, созрело время реально оценитьстепеньвлияния индивидуального налогообложения на неравенство в доходах и выработать механизмы совершенствования системы индивидуального подоходного налога в условиях социально-экономической модернизацииКазахстана.

Переход к всеобщему декларированию доходов физических лиц направлен на повышение собираемости налогов и противодействие 
теневой экономике, и этот процесс влечет за собой ряд преимуществ и недостатков, возможностей и рисков.

Поэтому, успешная реализация такого проекта, как всеобщее декларирование, использование той или иной шкалы напрямую зависит от грамотного подхода к управлению данными категориями.

Кроме того, особое значение имеет поиск и реализация таких возможностей, которые могут нейтрализовать имеющиеся противоречия и недостатки процесса внедрения всеобщего декларированиядоходов.

\section{Библиография}

Аббасова А., главный эксперт Управления разъяснения исовершенствования налогового законодательства НКМФРК. «Международный опыт всеобщего декларирования доходов и имущества физических лиц».

Alston, R.M., Kearl, J.R., Vaughan, M.B. (1992). Is There a Consensus Among Economists in the 1990s. Am. Econ. Rev., 82(2):203-209.

Барышева С.К. Проблемы и перспективы исчисления индивидуального подоходного налога. Вестник КарГУ. Г. Караганда. 2015.

Бобоев М.Р., Мамбеталиев Н.Т., Тютюрюков Н.Н. Налоговые системы зарубежных стран: Содружество Независимых Государств. Учебное пособие. М., Гелиос АРВ, 2002. - 624c.

Данные с официального сайта Комитета Государственных доходов РК за период 2010-2018 гг, kgd.gov.kz _...postupleniya-po-nalogam... byudzhet...2017...

Gorodnichenko, Y., Vazquez, J.M., Sabirianova, K.P. (2009). Myth and Reality of Flat Tax Reform: Micro Estimates of Tax Evasion Response and Welfare Effects in Russia. J. Pol. Econ., 3(117):504-554.

Информационное сообщение об изменениях в порядке налогообложения на 2009 г. Государственный Налоговый Комитет Узбекистанаhttp://www.soliq. uz/publish/news/1024.pdf.

James, A. Yunker Capital wealth taxation as a potential remedy for excessive capital wealth inequality // Journal of Post Keynesian Economics / Fall 2010, Vol. 33, No. 1,83-104.

Jin , J., Fitz Roy, F. J Econ (2017) 122:121-136 DOI 10.1007/s00712-017-0557-1.

Johnston, D.C. (2005). Taxes and Income Inequality «For tax Analysts». [http://www. tax.com/taxcom/features.nsf/Articles] accessed January 18 (2012):12. 
Казаков, В.В. Совершенствование налогообложения в России (наосновезарубежногоопыта). Вестник Томского Государственного университета - 2007.

Krajewski, P., Pił, K.. Does A Progressive PIT Stabilize The Economy? A Comparison Of Progressive And Flat Taxes.Comparative Economic Research, Volume 20, Number 1, 2017 10.1515/cer-2017-0002.

Курляндская Г. (2010). «Граждане с высокими доходами, по мысли депутатов, должны платить налоги по более высокой ставке, http:// www.ng.ru/ economics|2010-04-16.

Лукьянова, Н.И. Декларирование доходов государственными гражданскими служащими и членами их семей. Проблемы правоприменения // Лоббист . 2010. No 5.

Macek, R. / The Impact of Taxation on Economic Growth: Case/ Study of OECD Countries1Review of economic perspectives - národohospodářský obzor, vol. 14, issue 4, 2014, pp. 309-328, doi: 10.1515/revecp-2015-0002/.

Материалы Пятого Казахстанского налогового форума. 10.10.2010 г.

Minarik J. Tax Expenditures in OECD Countries / J. Minarik / Meeting of Senior Budget Officials, Vienna, 2 - 3 June 2008 [Электронныйресурс].- Режим доступа: http://www.oecd.org/dataoecd/21/14/41278667.ppt.- P.24.

Наненко И.С, Декларация о доходах, об имуществе и обязательных имущественного характера публичных должностных лиц, применение в России и в мире. Национальный исследовательский университет« Высшая школа экономики» 2012.

Назарбаев Н.А. Через кризис к обновлению и развитию: Послание Президента народу Казахстана на 2009 год [Электрон. ресурс] /Режим доступа:http:// www.akorda.kz.

Оценка влияния создания Таможенного союза (Республика Беларусь, Республика Казахстан, Российская Федерация) на конкурентоспособность казахстанской продукции, востребованной в сфере недропользования» Филиал «Контрактное агентство» АО «ГДУ НГП» г. Астана, 2010 годс. 21-22.

Ricketts M, Shoesmith E (1992). British Economic Opinion: Positive Science or Normative Judgment. Am. Econ. Rev., 82(2):210-215.

Roosevelt, F.D. Applied Economics Department-CP140 Free University of BrusselsOptimal income tax calculation: the case of belgium Malhemarical Modelling. Vol. 4, pp. 545-553. 1983 Printedinthe USA.

Сайт «Армянское агентство развития». Налогообложение физических лиц в Армении. http://www.ardani.net/armenia/armenia-taxation- it.php 
Сайт «Министерства по налогам АзербайджанскойРеспублики» http://www. taxes.gov.az/rus/qanun/mecelle.shtml

Shigehiro, O., Schimmack, U., Diener, E. (2012) Progressive Taxation and the Subjective Well-Being of Nations «Psychological Science» Jan 9, 2012.http://www.sagepublications.com.

Трудности запуска в Казахстане всеобщего декларирования доходов https:// kapital.kz> Финансы.

Умирбекова, Г. Мировой опыт: система налогообложения в США// Вестник налоговой службы Республики Казахстан, № 11 (75), ноябрь 2005 г., с. 23.

Всеобщее декларирование в Казахстане: очень много нерешенных проблем. www.millioner.kz).

Хасси У. М., Любик Д. С. Мировое налогообложение. Основы Мирового налогового кодекса [Текст]: Пер. с англ. - Кембридж: Гарвардский университет, 1992.-280.

\section{References}

Abbasova A, suspendisse peritus de declaratione et emendationem tributum leges tributum codice MF poweliks familia. "International experientia Declarationem reditus et possessiones singulorum".

Alston, R.M., Kearl, J.R., Vaughan, M.B. (1992). Est Consensus Inter Economists in in 1990s. Am. Econ. Rev., 82(2): 203-209.

Barysheva, S.K. Quaestiones et spes de ratione singulorum reditus.

Boboev, M.R., Mambetaliev, N.T., Tyutyuryukov, H.N. Tributum Unum.

Difficultates coepi in Kazakhstan Declarationem reditus https://kapital.kz "rebus Oeconomicis (access 01.09.2018).

Generalis Declaratio in Kazakhstan: illic es multus of reconditis problems. www.millioner.kz) (access 01.09.2018).

Gorodnichenko, Y., Vazquez, J.M., Sabirianova, K.P. (2009). Fabula et Re Flat Tax Reformationem: Micro Opiniones Tributum Fraudisque Auctor et Prosperitatis Effectus in Russia. J. Pol. Econ., 3(117): 504-554.

Hussey, W.M., Lubeck, D.S. Global vectigalibus. Fundamenta mundi tax code [Text]: Per. cum anglorum. - Cantabrigiae: Harvard University, 1992 - 280.

Iacobus, A. Yunker Capitis opes tributum, ut a potentia remedium nimia capitis opes inaequalitas // Acta Post Keynesian Parcus / Lapsum 2010, Vol. 33, N. 1, 83-104. 
Jin, J., Fitz Roy, F., Econ, R.J. (2017). Higher Tax for Top Earners, „Journal of Economics”, Springer, vol. 122(2), p. 121-136, October.121-136 DOI 10.1007/s00712-017-0557-1. Johnston, D.C. (2005). Vectigalia et Reditus Inaequalitas “tributum Analysts”. [http:// www.tax.com/taxcom/features.nsf/Articles] accessed January 18 (2012): 12.

Kazakov, V.V. Emendationem vectigalibus in Russia (substructio in experientiam international). Acta in Tomsk Publica University - 2007.

Krajewski, P., Pił, K. Non Gradatim LACUM Stabiliendum Oeconomia? A Comparatione, De Progressu, Et Plana Tributa. Comparative Oeconomicarum Research, Volume 20, Numero 1, 2017 10.1515/cer-2017-0002.

Kurlandskaya, G. (2010). “ Cives cum princeps prouentus, secundum legati, reddere vectigalia ad superiorem rate. http:// www.ng.ru/economics/2010-04-16 (access 01.09.2018).

Lukyanova, N.Et. Declaratio reditus per civilem servos et familias suas. Quaestiones egestas / / Lobbyist . 2010. No. 5.

Macek, R. / Ictum Vectigalibus in Oeconomica Augmentum: Casu/ Studio OECD Countries1Review aliquet prospectus - národohospodářský obzor, vol. 14, exitus 4, 2014, pp. 309-328, doi: 10.1515/revecp-2015-0002/.

Maurisarutrum Civitatis reditus Ipsum Reipublicae Kazakhstan enim tempus 2010-2018, kgd.gov.kz»...postupleniya-po-nalogam...byudzhet 2017.......

Minarik, J. Tributum Expensi in OECD Terris / J. Minarik / Conventus Senior Nibh Officiales, Vienna, 2 - 3 June 2008 [Электронныйресурс]. - Режимдоступа: http://www.oecd.org/dataoecd/21/14/41278667.ppt.- P. 24 (access 01.09.2018).

Nazarbayev, N.Ah. Per discrimen, ad renovationem et incrementum: Praesidis Oratio ad populum Kazakhstan pro 2009 [Electron. resource] / obvius Modum: http:// www.akorda.kz mmm. (access 01.09.2018).

Notitia nuntius mutationes in vectigalibus procedendi pro 2009 Statu Tributum Ipsum Uzbekistan http://www.soliq.uz/publish/news/1024.pdf.

Rebus Quinto Kazakhstan tributum forum. 10.10.2010 g.

Ricketts, M., Shoesmith, E. (1992). British Aliquet Sententia: Positivum Scientia vel Committit Iudicium. Am. Econ. Rev., 82(2): 210-215.

Roosevelt, F.D. Applicata Parcus Department-CP140 Libero Universitatis BrusselsOptimal reditus tributum ratione: casu belgium Malhemarical Sculpturae. Vol. 4, pp. 545-553. 1983 Typis in USA.

Shigehiro, O., Schimmack, G., Diener, E. (2012). Progressivum Vectigalibus et Su- 
biectiva Bene Esse Gentes “Animi Scientia” Jan 9, 2012. http://www.sagepublications.com. (access 01.09.2018).

Taxationem ictum instauratione Moribus Unione (Reipublicae Belarus, Reipublicae Kazakhstan, Russian Foederatio) in aemulationes Kazakh products in demanda in agro subsoil uti" Ramus "Contractus Opera" JSC "GDU NGP” Astana, 2010 c. $21-22$

Umirbekova, G. Experientia in mundo: vectigalibus in Iunctus Civitas// Acta tributum obsequium Reipublicae Kazakhstan, № 11 (75), November 2005, p. 23.

Website "armenius development Agency". Vectigalibus singulorum in Armenia. http://www.ardani.net/armenia/armenia-taxation - it.php (access 01.09.2018).

Website Ministerii of taxes Reipublicae Adrabigania http://www.taxes.gov.az/rus/qanun/mecelle.shtml. (access 01.09.2018).

Yanenko, I. Declaratio de prouentus, in proprietate et ligare res publica principes, applicatio in Russia et in mundo. National research University" Altior schola Parcus" in 2012. 